\title{
Feasibility of Thermoelectrics for Waste Heat Recovery in Conventional Vehicles
}

Technical Report NREL/TP-540-44247 April 2009

K. Smith and M. Thornton

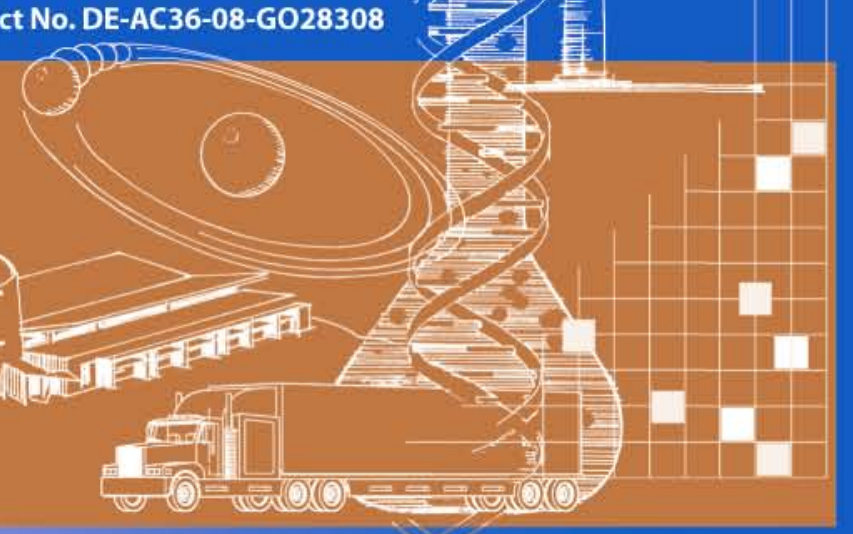




\section{Feasibility of Thermoelectrics for Waste Heat Recovery in Conventional Vehicles}

Technical Report NREL/TP-540-44247

April 2009

K. Smith and M. Thornton

Prepared under Task No. FC08.2000

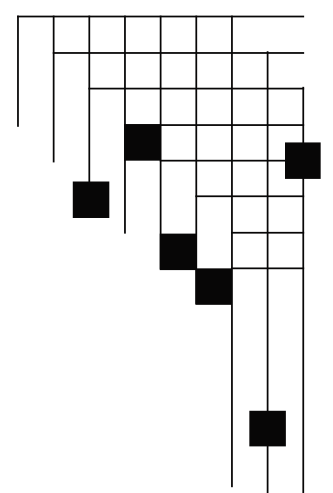

National Renewable Energy Laboratory

1617 Cole Boulevard, Golden, Colorado 80401-3393

303-275-3000 • www.nrel.gov

NREL is a national laboratory of the U.S. Department of Energy

Office of Energy Efficiency and Renewable Energy

Operated by the Alliance for Sustainable Energy, LLC

Contract No. DE-AC36-08-GO28308 


\section{NOTICE}

This report was prepared as an account of work sponsored by an agency of the United States government. Neither the United States government nor any agency thereof, nor any of their employees, makes any warranty, express or implied, or assumes any legal liability or responsibility for the accuracy, completeness, or usefulness of any information, apparatus, product, or process disclosed, or represents that its use would not infringe privately owned rights. Reference herein to any specific commercial product, process, or service by trade name, trademark, manufacturer, or otherwise does not necessarily constitute or imply its endorsement, recommendation, or favoring by the United States government or any agency thereof. The views and opinions of authors expressed herein do not necessarily state or reflect those of the United States government or any agency thereof.

Available electronically at http://www.osti.gov/bridge

Available for a processing fee to U.S. Department of Energy and its contractors, in paper, from:

U.S. Department of Energy

Office of Scientific and Technical Information

P.O. Box 62

Oak Ridge, TN 37831-0062

phone: 865.576 .8401

fax: 865.576 .5728

email: mailto:reports@adonis.osti.gov

Available for sale to the public, in paper, from:

U.S. Department of Commerce

National Technical Information Service

5285 Port Royal Road

Springfield, VA 22161

phone: 800.553.6847

fax: 703.605.6900

email: orders@ntis.fedworld.gov

online ordering: http://www.ntis.gov/ordering.htm 


\section{Acknowledgments}

The authors gratefully acknowledge funding from the U.S. Department of Energy Vehicle Technologies Program under the Advanced Vehicle Technology Analysis and Evaluation Activity. We also appreciate the support and contributions of Lee Slezak, Technology Manager. 


\section{Executive Summary}

Thermoelectric (TE) generators convert heat directly into electricity when a temperature gradient is applied across the junctions of two dissimilar metals. These devices have the potential to increase the fuel economy of conventional vehicles by recapturing a portion of the waste heat from the engine exhaust and generating electricity to power a vehicle's accessory loads.

At present, device efficiencies are low ( $\sim 5 \%)$; however, thin-film and quantum well technologies offer the possibility of higher efficiency in the future ( 10\% to $15 \%)$. Four vehicle platforms are considered: a midsize car, a midsize sport utility vehicle, a Class 4 truck, and a Class 8 truck. A simple vehicle and engine waste heat model shows that the Class 8 truck presents the least challenging requirements for TE system efficiency, mass, and cost. This is because Class 8 trucks have a relatively large amount of exhaust waste heat, have low mass sensitivity, and travel a high number of miles per year, all of which help to maximize fuel savings and economic benefits.

A driving and duty cycle analysis for the Class 8 truck elucidates trade-offs in system sizing and shows the strong sensitivity of waste heat, and thus TE system electrical output, to vehicle speed and driving cycle. It is not feasible for a TE system to replace the alternator, as too little waste heat is available during city driving and/or idling.

Together with a typical alternator, a TE system could enable the electrification of $8 \%$ to $15 \%$ of a Class 8 truck's accessories, providing 2\% to 3\% fuel savings. Additional electrification would require a larger alternator and battery to augment the TE system so that adequate electrical power is available during low-speed driving and idling. Achieving an economic payback in three years dictates that the TE system cost less than roughly $\$ 450 / \mathrm{kW}$, requiring an almost tenfold reduction from today's costs. Such a cost reduction might be enabled in the future by thin-film devices that use expensive TE junction materials more efficiently. 


\section{Table of Contents}

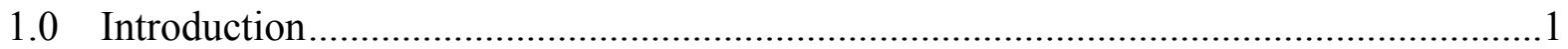

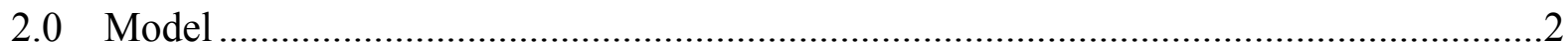

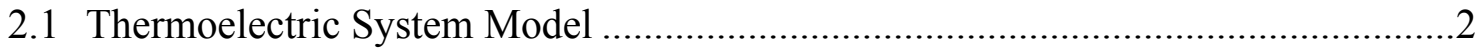

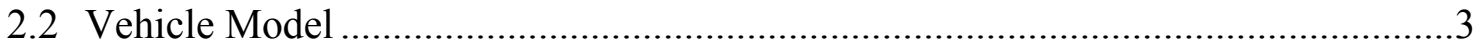

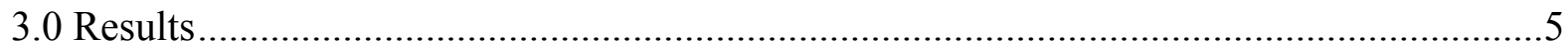

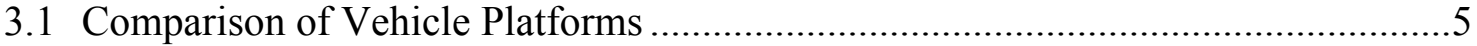

3.2 Duty and Driving Cycle Analysis for Class 8 Truck.............................................

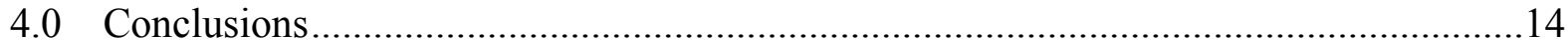

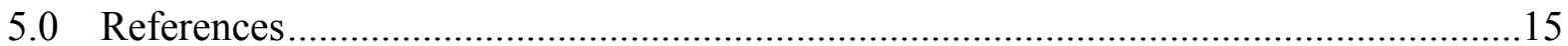




\section{List of Figures}

1. Conversion efficiency of a thermoelectric device vs. figure of merit, $Z T$........................... 3

2. Schematic of vehicle system model ...........................................................................

3. Data from a caterpillar C12 engine (overlay), shown in comparison to results of the exhaust waste heat model.......................................................................................

4. Fuel savings under scenarios in which some or all of the engine's mechanically driven accessories are replaced with electrically driven accessories .............................................6

5. TE system cost and mass required to achieve 3-year economic payback (i.e., recovering TE system initial cost through fuels savings)

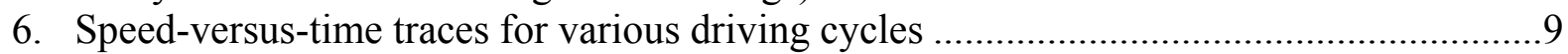

7. Fraction of time spent above a given speed for various driving cycles .............................. 8

8. Percentage of time that a Class 8 truck spends above various levels of engine power

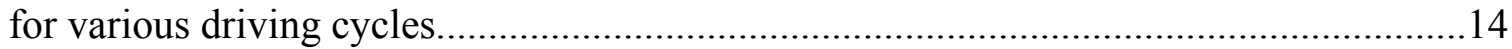

9. Contour lines showing average electrical power, $P_{\text {elec, avg }}(\mathrm{kW})$, generated by a TE System with conversion efficiency, $\eta_{T E}$ sys. $=10 \%$ for a Class 8 truck ...........................15

\section{List of Tables}

1. Parameters for Four Vehicle Platforms in the Study .5

2. TE System Conversion Efficiencies Required to Eliminate the Alternator (Scenario 1) and Electrify All Accessories (Scenario 2) for 20-mph Steady-State Driving

3. Average TE System Electrical Power for a Class 8 Truck under Different Driving Scenarios and TE System Conversion Efficiencies

4. Feasible Accessory Electrification Scenarios for a Class 8 Truck Incorporating TE Systems with Various Conversion Efficiencies 


\section{Introduction}

Waste heat recovery devices can increase vehicle fuel economy by converting a portion of engine waste heat to useful work. Taking a conventional example, a turbocharger expands hot exhaust gases through a turbine and uses this shaft power to compress engine intake air and boost engine efficiency. Though they are not used in vehicles at present, adsorption and absorption refrigeration systems provide potential pathways to convert engine waste heat into passenger cabin cooling [1,2], eliminating engine loads associated with traditional vapor-compression systems.

Thermoacoustic devices $[3,4]$ provide a pathway to convert waste heat to sound and then to cooling or, if combined with a linear motor or piezoelectric generator, electricity. Thermoelectric (TE) devices, the subject of this report, offer an attractive direct conversion path from heat to electricity, with no moving parts [5]. This direct conversion of heat to electricity, combined with recent laboratory advances in efficiency, makes TE devices an interesting candidate for automotive waste heat recovery [6].

While TE generators have the potential to increase vehicle fuel economy by converting a portion of engine waste heat to electricity $[7,8]$, that electricity can be used in several ways.

Conventional vehicles could derive a fuel economy benefit by using the extra electrical power to reduce alternator loads and/or electrically drive accessories such as power steering [9]. Hybrid electric vehicles (HEVs) might also use the extra electrical power to directly assist with vehicle propulsion [10].

A typical engine wastes approximately two-thirds of the fuel's combustion energy as heat. Some waste heat is transferred to the coolant system and/or carried from the engine block by convection and radiation. Although waste heat could potentially be recovered from the coolant system, the relatively low difference in temperature from ambient would result in low TE generator efficiency. This work assumes that the TE generator recovers heat from the engine exhaust, which has the highest temperature and, consequently, the most thermodynamically available waste heat.

In most vehicle applications currently being explored, the TE device employs heat exchangers to carry heat from the exhaust system to the hot side of the device (and isolate the device from peak exhaust system temperatures) as well as to remove heat from the cold side of the device [8, 11]. The cold side commonly uses ethylene glycol as a working fluid, either shared with the engine cooling loop or using its own dedicated radiator.

This report provides a simplified analysis in which the energy conversion efficiencies of the TE device and associated heat exchangers, pumps, and other components are lumped into a single conversion efficiency representative of the entire TE system. In the analysis, four vehicle platforms - a midsize sedan, a midsize sport utility vehicle, a Class 4 truck, and a Class 8 truck - are initially considered. A more detailed analysis of waste heat availability for the Class 8 truck under various duty cycles then follows. 


\subsection{Model}

\subsection{Thermoelectric System Model}

First discovered by Thomas Johann Seebeck in 1821, a thermoelectric device generates electricity when a temperature gradient is applied across the junctions of two dissimilar metals. The performance of the device, determined by properties of the junction materials, is typically stated using a figure of merit, $Z T$. Yang [6] gives a timeline of advances in thermoelectric materials and their figures of merit. Bulk materials, such as bismuth telluride and lead telluride, which were identified in the $1960 \mathrm{~s}$ and $1970 \mathrm{~s}$, have a $Z T$ in the range of 0.5 to 1.0 . These materials are most common in current applications, including vehicle waste heat recovery demonstration programs.

More recently discovered thin-film materials, such as silicon carbon and boron carbon operating on a quantum well principle, have demonstrated a $Z T$ of 4 to 5 in the laboratory, but designs that use these materials have yet to be scaled up to practical systems. In addition to higher efficiency, these thin-film designs offer the potential for much lower cost in comparison to bulk designs because less junction material is required; however, they usually have higher manufacturing costs.

The efficiency of a TE device is the amount of electrical power generated for a given amount of heat input, $\eta_{T E}=P_{\text {elec }} / P_{h, i n}$. This efficiency can be calculated as a function of the hot-side temperature, $T_{h}$, the cold-side temperature, $T_{c}$, and $Z T$ as [12]

$$
\eta_{T E}=\frac{T_{h}-T_{c}}{T_{h}} \frac{\sqrt{1+Z T}-1}{\sqrt{1+Z T}+T_{c} / T_{h}} .
$$

Figure 1 gives the TE device efficiency for a system with $T_{c}=95^{\circ} \mathrm{C}$ and various $T_{h}$. A $Z T$ in the range of 0.85 to 1.25 gives device efficiencies from $5 \%$ to $12 \%$. The lower end of that range may be taken as present-day capability, while the upper end represents future capability. In an optimistic future scenario, thin-film devices might approach $20 \%$ efficiency.

In a vehicle application, the overall system efficiency, $\eta_{T E}$ sys $=P_{\text {elec }} / P_{\text {exh }}$, where $P_{\text {exh }}$ is the engine exhaust heat, will be less than the device efficiency. This difference is due to exhaust line temperature drops $(\Delta T)$ between the engine and the TE system, cold- and hot-side heat exchanger effectiveness $\varepsilon<1$, and parasitic losses due to pumps and electric power conversion devices. Given these losses, it is reasonable to expect that the efficiency of a complete system, $\eta_{T E ~ s y s}=f\left(\eta_{T E}, \Delta T, \varepsilon, P_{\text {pumps }}, \ldots\right)$, might be only half that of the thermoelectric device, $\eta_{T E}$.

To complete a large design space search across multiple vehicle platforms, the current model neglects losses due to heat exchangers, pumps, and so forth. Instead, a simple "black box" TE system model is used to predict the TE system's electrical power output, $P_{\text {elec }}$, as a function of the engine's rate of exhaust heat output, $P_{e x h}$, as

$$
P_{\text {elec }}=\min \left(\eta_{T E \text { sys }} P_{\text {exh }}, P_{\max , T E s y s}\right) .
$$


TE system efficiency, $\eta_{T E \text { sys }}$, and TE system maximum power output rating, $P_{\max }$, TE sys, are both treated as constant parameters for a given design.

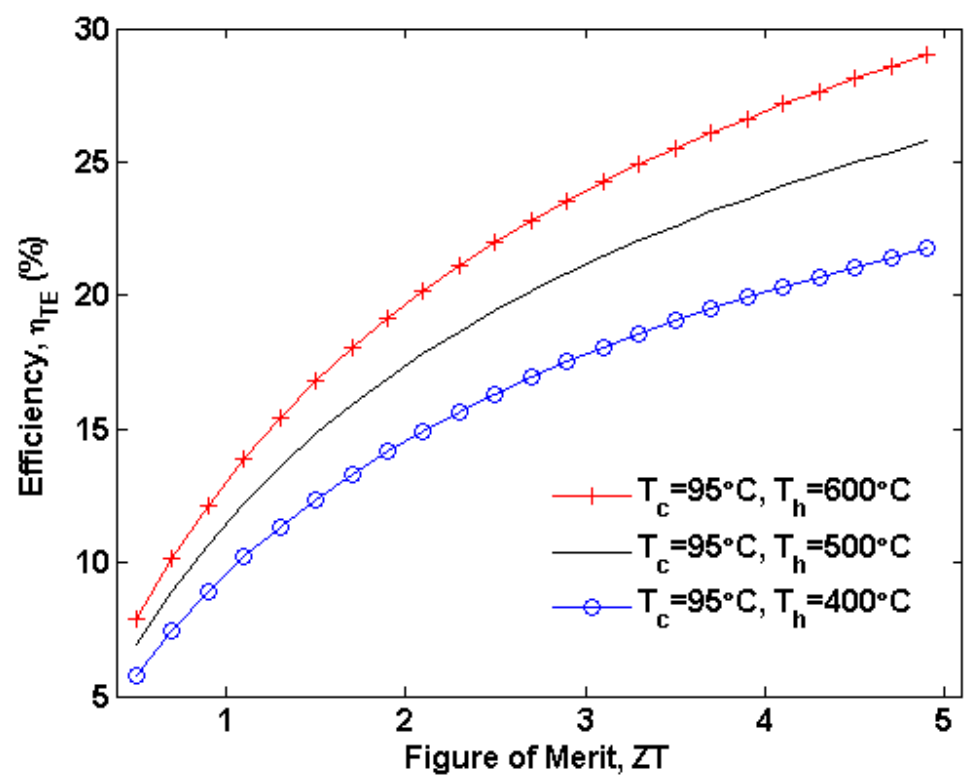

Figure 1. Conversion efficiency of a thermoelectric device vs. figure of merit, $Z T$

\subsection{Vehicle Model}

The vehicle model consists of simple road load, engine waste heat, and driveline models. A schematic of the model, including the TE system, is given in Figure 2. Only a small portion of the vehicle's fuel input energy is converted to useful work to drive the wheels and accessory loads. In a conventional vehicle, fuel may be saved by reducing the mechanical accessory load on the engine, $P_{a c c, \text { mech }}$, and using power generated by the TE system to drive some or all accessories with electricity, $P_{a c c, \text { elec }}$, instead. The power required at the wheels to drive the vehicle at speed, $v$, is

$$
P_{\text {wheels }}=v\left(F_{\text {aero }}+F_{\text {roll }}+m \frac{d v}{d t}\right)
$$

where the aerodynamic drag and rolling resistance forces are, respectively,

$$
\begin{aligned}
& F_{\text {areo }}=\frac{1}{2} \rho_{\text {air }} C_{d} A_{f} v^{2}, \\
& F_{\text {roll }}=m g \cos (\theta) a .
\end{aligned}
$$

The power at the wheels is met by engine power, $P_{\text {eng }}$, transferred to the wheels through a driveline with efficiency, $\eta_{d r v},=85 \%$ :

$$
P_{\text {wheels }}=\left(P_{\text {eng }}-P_{a c c, \text { mech }}\right) \eta_{d r v} .
$$

In addition to meeting road loads, the engine must also drive accessories consuming power, $P_{\text {acc mech. }}$ Engine power is calculated as 


$$
P_{\text {eng }}=\eta_{\text {eng }} \dot{m}_{\text {fuel }} L H V_{\text {fuel }} \text {, }
$$

where the engine efficiency and fuel flow rate are interpolated from empirical engine maps as a function of engine power and speed. Engine exhaust waste heat power output is calculated as

$$
P_{\text {exh }}=P_{\text {eng }}\left(1-\eta_{\text {eng }}\right) r,
$$

where $r$ is the fraction of engine waste heat exiting through the engine exhaust. As shown in Figure 3, we fit $r$ to engine exhaust temperature and flow rate data for a diesel engine and obtain an adequate fit with $r=0.30$ at low torque and 0.46 at peak torque. Values of $r$ are interpolated for intermediate torques. The model suggests that $54 \%$ to $70 \%$ of total engine waste heat is dissipated by the coolant system, and convection and radiation from the engine block.

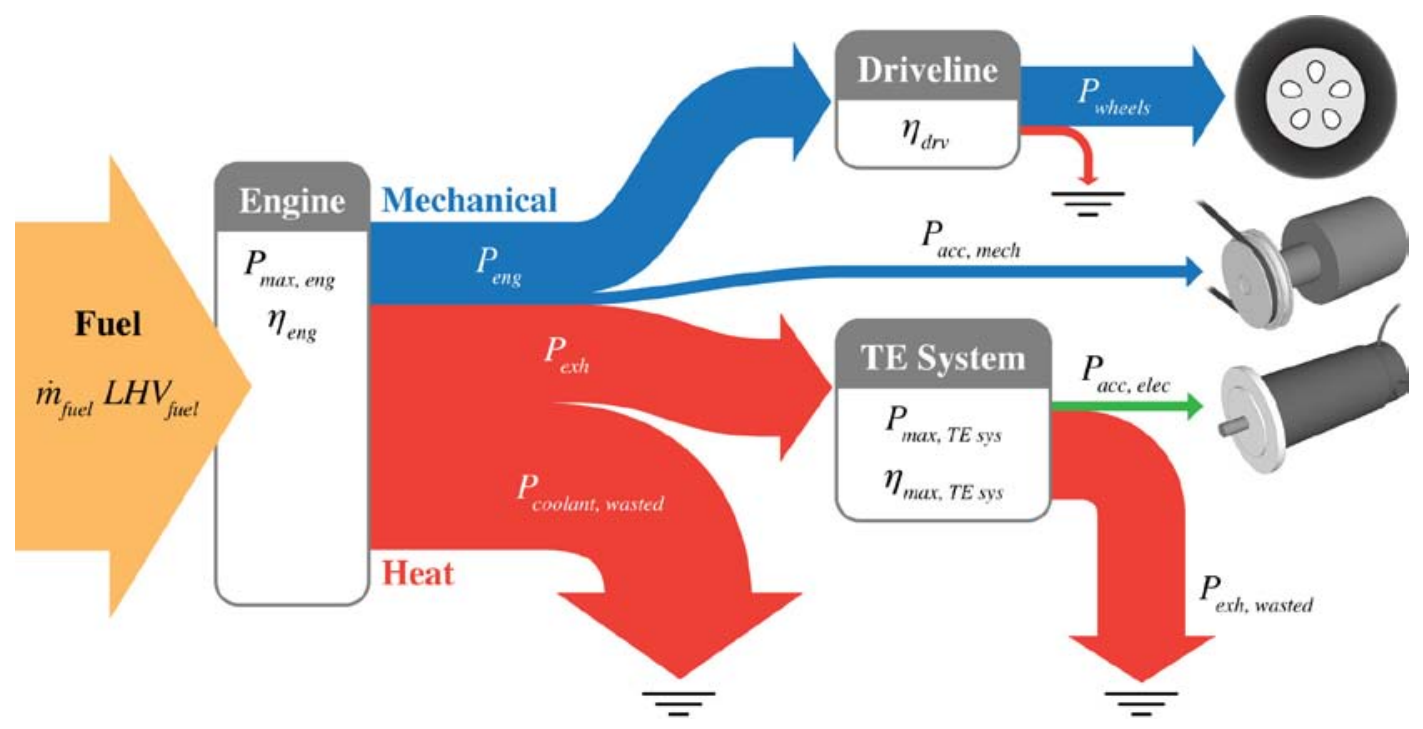

Figure 2. Schematic of vehicle system model. Only a small percentage of fuel input energy is converted to useful work, powering the wheels and accessory loads.

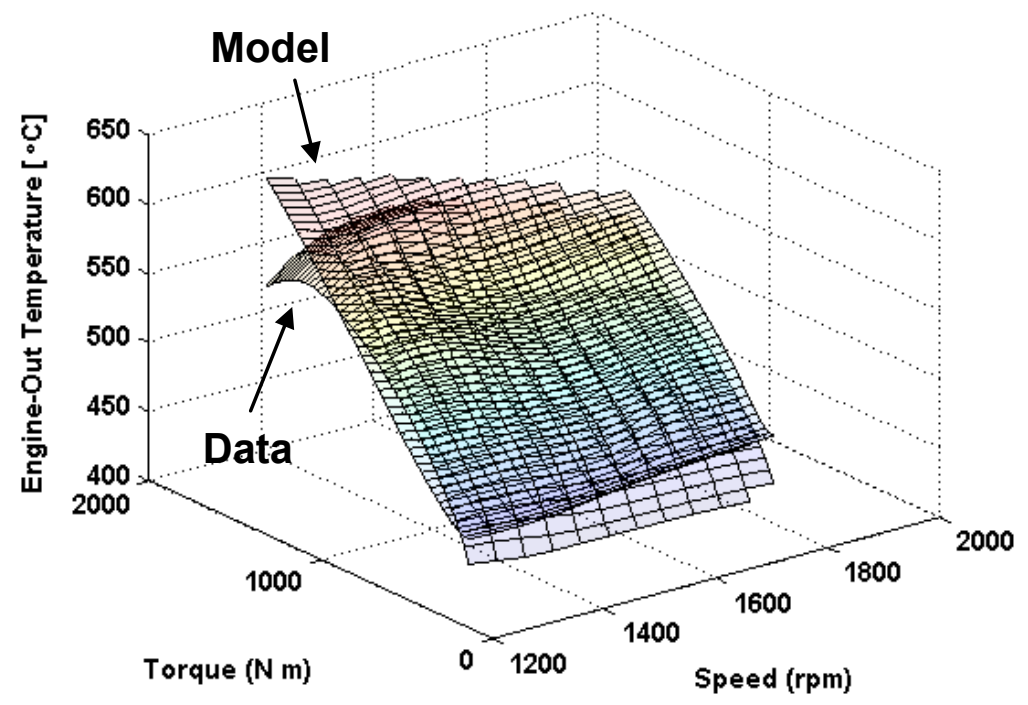

Figure 3. Comparison of the exhaust waste heat model with data from a Caterpillar C12 engine 


\subsection{Results}

Four vehicle platforms are compared on the basis of potential fuel savings and waste heat availability to determine which one might be best suited for early integration of TE systems. Table 1 gives the model parameters used for a midsize sedan, a midsize sport utility vehicle (SUV), a Class 4 truck, and a Class 8 truck. The midsize sedan and midsize SUV are assumed to be powered by gasoline/spark-ignition engines; the Class 4 and 8 trucks are powered by more efficient diesel/compression-ignition engines. The Class 8 truck is found to present the least stringent TE system requirements in terms of cost, mass, and efficiency. The Class 8 truck is therefore investigated further for specific scenarios to select the TE system size and investigate the sensitivity of those scenarios to driving and duty cycles.

Table 1. Parameters for Four Vehicle Platforms in the Study

\begin{tabular}{lcccc}
\hline & $\begin{array}{c}\text { Midsize } \\
\text { Sedan }\end{array}$ & $\begin{array}{c}\text { Midsize } \\
\text { SUV }\end{array}$ & $\begin{array}{c}\text { Class 4 } \\
\text { Truck }\end{array}$ & $\begin{array}{c}\text { Class 8 } \\
\text { Truck }\end{array}$ \\
\hline Test mass, $m_{\text {veh }}(\mathrm{kg})$ & 1565 & 2151 & 7700 & 36,300 \\
Frontal area, $A_{f}\left(\mathrm{~m}^{2}\right)$ & 2.27 & 2.88 & 6.89 & 8.55 \\
Drag coefficient, $C_{d}$ & 0.30 & 0.41 & 0.7 & 0.7 \\
Rolling resistance coefficient, a & 0.009 & 0.009 & 0.009 & 0.009 \\
Engine type & gasoline & gasoline & diesel & diesel \\
Engine power, $P_{\text {max, eng. }}(\mathrm{kW})$ & 121 & 135 & 149 & 332 \\
Alternator accessory load $(\mathrm{kW})$ & 0.55 & 0.55 & 0.6 & 0.7 \\
Total accessory load $(\mathrm{kW})$ & $2.47^{\mathrm{a}}$ & $2.86^{\mathrm{a}}$ & 4.0 & $7.1^{\mathrm{a}}$ \\
Vehicle miles travelled $(\mathrm{mi} / \mathrm{yr})$ & 12,240 & 12,240 & 18,720 & 80,000 \\
\hline
\end{tabular}

a. Includes air conditioning with $50 \%$ duty cycle.

\subsection{Comparison of Vehicle Platforms}

To obtain rough bounds on potential fuel savings of TE systems, we initially ignore power and efficiency limits of practical TE system designs. Fuel savings are predicted under two simple scenarios: Scenario 1 unloads the engine by eliminating the alternator; scenario 2 unloads the engine by eliminating all mechanically driven accessories, including the alternator, power steering pump, and air conditioning compressor. In both scenarios, engine peak power is slightly downsized, commensurate with the reduced average engine power requirement; this downsizing provides additional fuel savings, as the smaller engine operates at a higher efficiency. Each scenario assumes that ample electrical power is available (either from a TE system or elsewhere) and that the vehicle mass remains the same as that of the baseline vehicle. In this way, the fuel savings predicted are the best possible for a TE waste heat recovery system integrated into a conventional vehicle.

Figure 4 shows fuel savings for the four vehicles traveling at various constant speeds. The savings that can be achieved under scenario 1 are modest, at approximately $1 \%$ to $3 \%$; the savings achievable under scenario 2 are appreciable, however, at approximately $3 \%$ to $15 \%$, depending on speed and vehicle platform. On average, the gasoline-fueled vehicles derive a slightly higher benefit than diesel-fueled vehicles, because the gasoline-fueled vehicles have less efficient engines. 
Scenario 1:

Eliminate Alternator

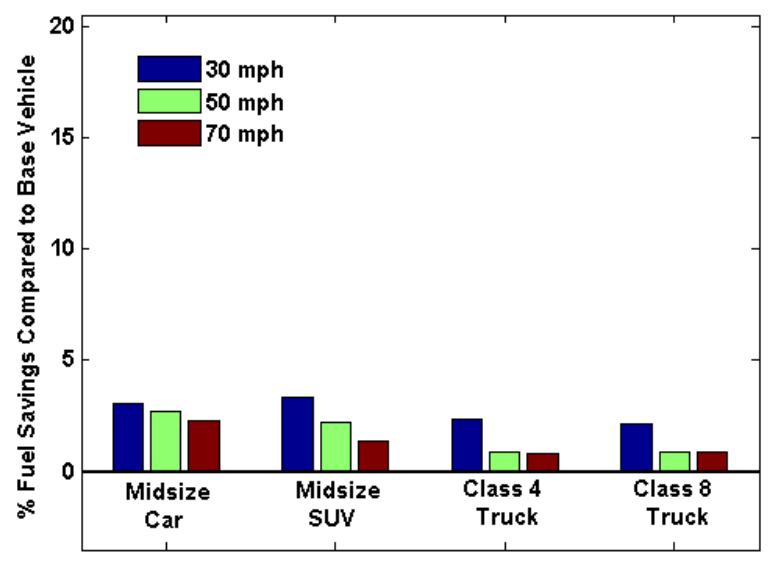

Scenario 2:

Electrify All Accessories

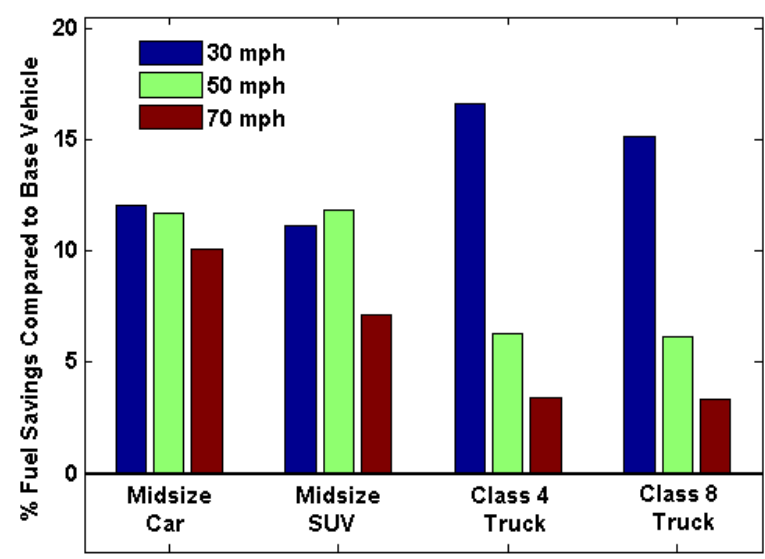

Figure 4. Fuel savings under scenarios in which some or all of the engine's mechanically driven accessories are replaced with electrically driven accessories. Assumptions: (1) sufficient electricity available from the TE system; (2) no increase in vehicle mass with addition of TE system.

In terms of cost and mass requirements imposed on a TE system, the Class 8 truck holds advantages over the other vehicle platforms in that this vehicle presents the least challenging requirements for early market introduction. Figure 5 shows the break-even TE system costs, in which a vehicle with a TE system will pay for its initial cost out of three years of fuel savings. For now, we assume that waste heat and TE system performance are sufficient to realize all of the fuel savings shown in Figure 4, though this is typically not the case. The break-even cost is expressed as a function of TE system mass because, for the same efficiency and operating characteristics, a heavier TE system will achieve less fuel savings as its extra mass penalizes vehicle efficiency.

Note that the allowable TE system mass shown on the y-axis of Figure 5 should not be taken as absolute, because those results are calculated using a steady-state model predicting less mass sensitivity than expected under transient operation. However, the constant speed results are still useful for comparing the relative merits of each vehicle platform.

In Figure 5, the results across vehicle platforms show a relative trend separating the Class 8 truck from the other vehicles. Under both scenarios, the heavy Class 8 truck can tolerate a higher TE system mass $(\mathrm{kg} / \mathrm{kW})$ and still achieve fuel savings. The higher number of vehicle miles traveled per year also means that the Class 8 truck will achieve larger aggregate fuel savings within a three-year payback period. The TE system can thus bear a higher cost $(\$ / \mathrm{kW})$ and still be economically acceptable.

Note also that scenario 1 tolerates much higher TE system costs than scenario 2 does. At early market introduction, when TE system costs are expected to be the highest, a modest level of waste heat recovery is economically favorable in comparison to aggressive levels. Because today's commercially available TE devices cost on the order of $\$ 3000$ to $\$ 6000 / \mathrm{kW}[13,14]$, costs must still be reduced considerably for vehicular waste heat recovery applications to become economically favorable. 


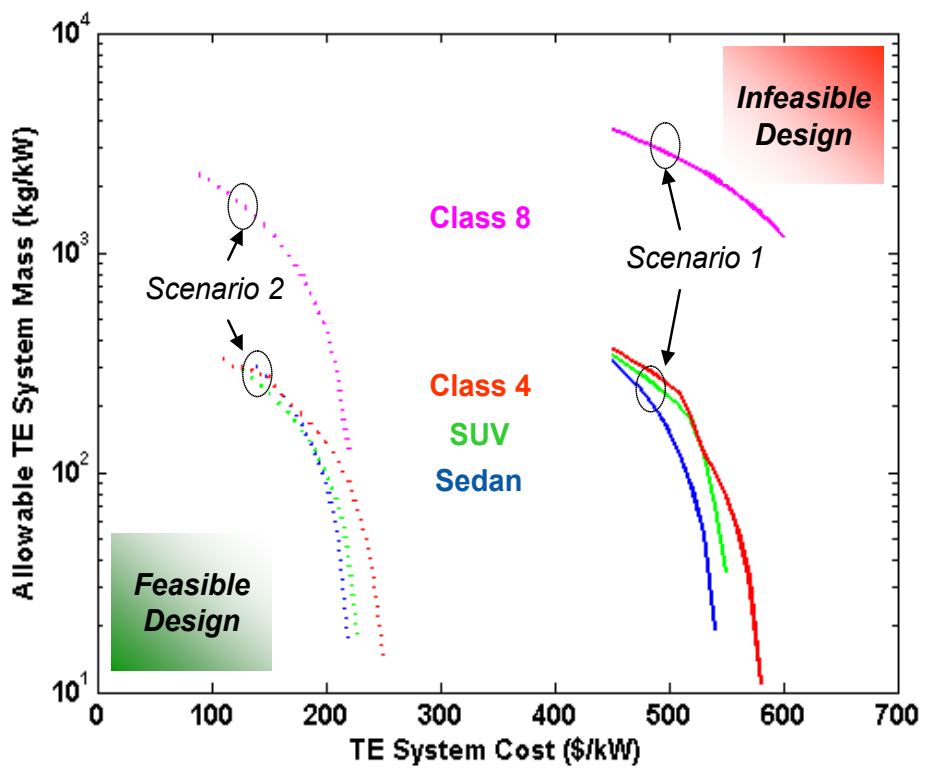

Figure 5. TE system cost and mass required to achieve 3-year economic payback (i.e., recovering TE system initial cost through fuel savings). Heavy systems will negate a portion of potential fuel savings and thus must have a lower initial cost to be economically feasible. Assumptions: (1) sufficient electricity available from the TE system; (2) steady-state operation at $50 \mathrm{mph}$; (3) 2006 average fuel prices: $\$ 2.58 / \mathrm{gal}$. gasoline, $\$ 2.71 / \mathrm{gal}$. diesel; (4) alternator: $\$ 400 / \mathrm{kW}, 20 \mathrm{~kg} / \mathrm{kW}$.

Results thus far have not addressed whether adequate exhaust waste heat is available to achieve a given accessory electrification scenario. Dividing the required electrical power by the amount of waste heat available at various vehicle speeds provides an estimate of the overall TE system conversion efficiency (including heat exchangers, pumps, and all other ancillaries) necessary for a given scenario. Waste heat is strongly dependent on vehicle speed, scaling with vehicle speed to the third power. Low-speed driving requires little power from a vehicle's engine and is accompanied by a small amount of waste heat. The most challenging efficiency requirement for a TE system will be to generate the required amount of electricity at low vehicle speeds. Though not considered in this report, it is worth noting that TE systems are best matched to electrify accessory loads that increase with the speed of the vehicle.

For comparison purposes, Table 2 gives the TE system conversion efficiencies necessary to eliminate the alternator (scenario 1) and electrify all accessories (scenario 2) for $20 \mathrm{mph}$ steadystate driving. Assuming that TE system efficiency (estimated to be around one-half of TE device efficiency because of ancillary losses) might at best approach 10\% in the future, Table 2 shows that the available waste heat is insufficient for complete accessory electrification in low-speed driving situations.

Less aggressive partial accessory electrification scenarios might be possible, depending on how often higher vehicle speeds are attained. Comparing across vehicle platforms, the Class 8 truck presents the least challenging conversion efficiency requirement because of the large amount of waste heat available in its exhaust. Smaller vehicles and/or vehicles with highly efficient engines generate less waste heat and require higher TE system conversion efficiencies to generate a fixed amount of electrical power. 
Table 2. TE System Conversion Efficiencies Required to Eliminate the Alternator (Scenario 1) and Electrify All Accessories (Scenario 2) for 20-mph Steady-State Driving

\begin{tabular}{lcc}
\hline & $\begin{array}{c}\text { Scenario 1: } \\
\text { Eliminate Alternator }\end{array}$ & $\begin{array}{c}\text { Scenario 2: } \\
\text { Electrify All Accessories }\end{array}$ \\
\hline Class 8 truck & $2 \%-3 \%$ & $20 \%-35 \%$ \\
Class 4 truck & $5 \%-8 \%$ & $30 \%-60 \%$ \\
Midsize SUV & $5 \%-6 \%$ & $20 \%-40 \%$ \\
Midsize sedan, & $4 \%-10 \%$ & $20 \%-45 \%$ \\
nominal engine (121 kW) & $7 \%-12 \%$ & $30 \%-55 \%$ \\
$\quad \begin{array}{l}\text { Midsize sedan, } \\
\text { small engine (75 kW) }\end{array}$ & $7 \%$ & \\
\hline
\end{tabular}

\subsection{Duty and Driving Cycle Analysis for Class 8 Truck}

As discussed above, the Class 8 truck platform holds multiple advantages over the other platforms considered, which makes it the most attractive application for early market introduction of a TE waste heat recovery system. Although the remainder of this analysis focuses on the Class 8 truck, the approach and discussion generally apply to the other vehicle platforms. This section assesses the quantity of waste heat available under various driving situations, determines an appropriate TE system size, and evaluates the level of accessory electrification that is practical for a Class 8 truck.

Figure 6 shows speed-versus-time traces for the eight different driving cycles used in this analysis. Given that waste heat is strongly dependent on vehicle speed, Figure 7 quantifies the cumulative percentage of time spent above various speeds for eight different driving cycles. For discussion purposes, the cycles are grouped on the basis of their speed-time statistics into three classifications: city cycles, suburban cycles, and highway cycles. These cycles are plotted in red, blue, and magenta, respectively, in Figure 7.

Each of the two highway cycles shows a vehicle being driven more than $50 \%$ of the time at greater than $40 \mathrm{mph}$; this suggests that, in highway driving situations, it might be advantageous to size the TE system to capture the amount of waste heat available at $40 \mathrm{mph}(\sim 55 \mathrm{~kW}$ for the Class 8 truck). In practice, we want to avoid sizing a TE system too small or too large for expected driving situations. For example, a 40-mph-peak waste heat design would be too small to make complete use of the waste heat available at speeds higher than that. Conversely, the same TE system would be oversized for city driving situations. In these low-speed situations, a smaller, lighter, and less expensive TE system would be more appropriate.

In practice, exhaust waste heat depends not just on the vehicle speed but also on the magnitude and frequency of acceleration events. City and suburban cycles in particular contain frequent acceleration events that are important to characterize. For the Class 8 truck, Figure 8 presents the percentage of time spent above a given level of exhaust power, predicted using a transient vehicle model that captures the exhaust waste heat produced during acceleration and deceleration events. Compared with Figure 6, Figure 8 shows less separation between the highway cycles and the city and suburban cycles because acceleration events are more frequent in low-speed cycles. 

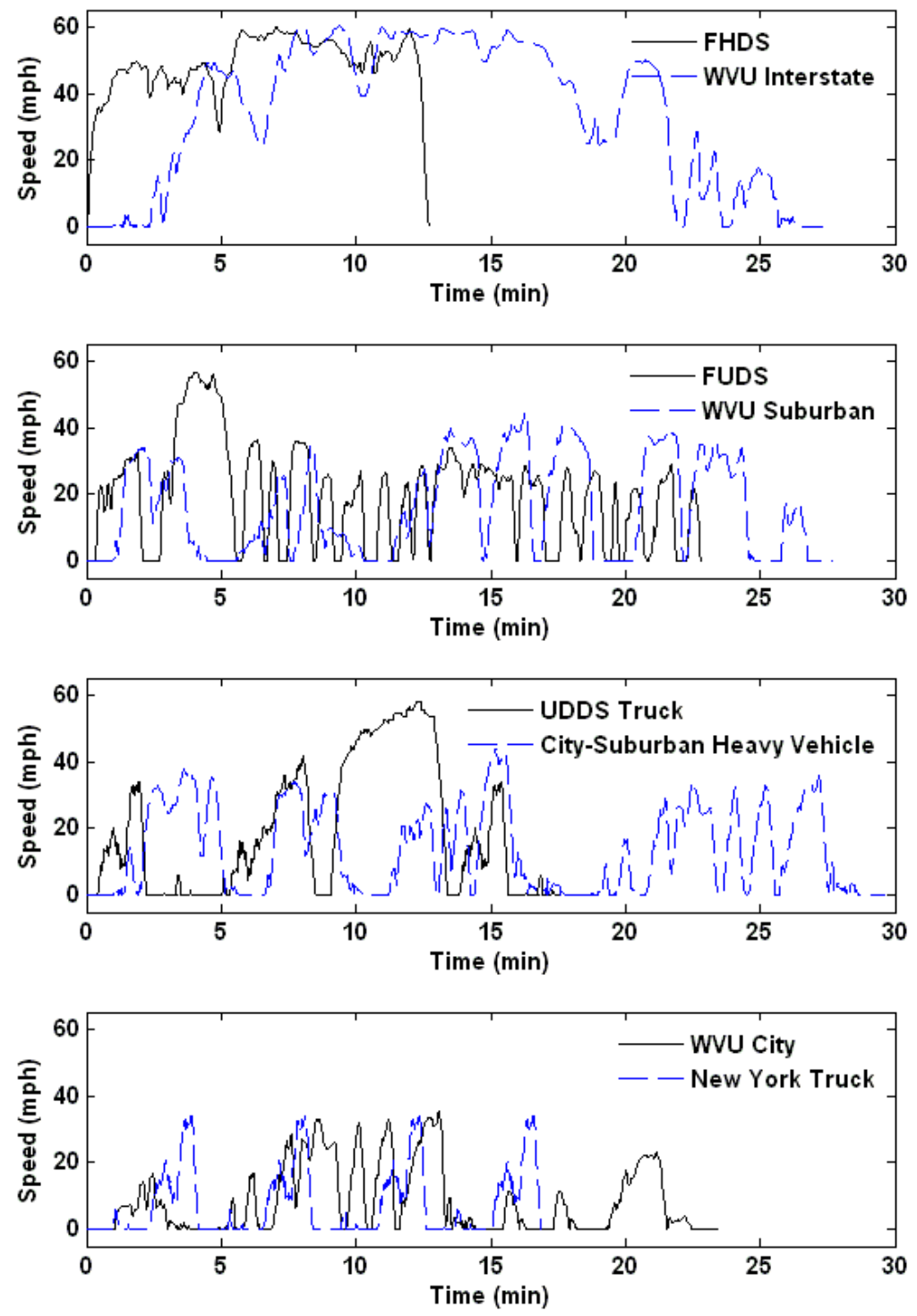

Figure 6. Speed-versus-time traces for various driving cycles 


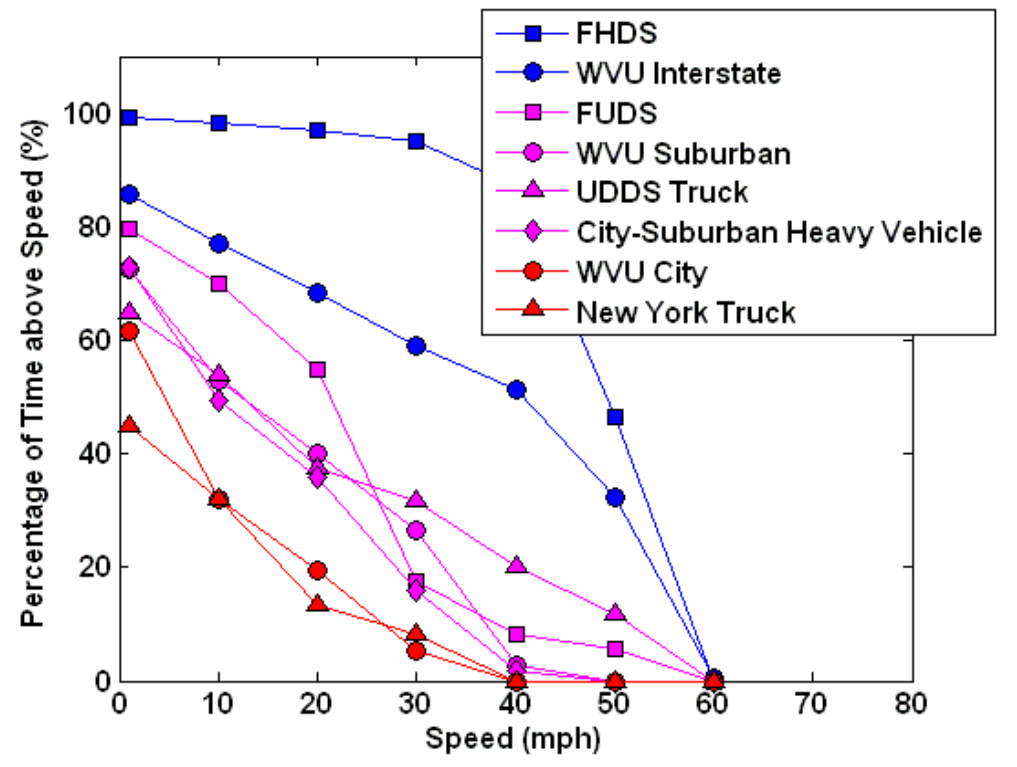

Figure 7. Fraction of time spent above a given speed for various driving cycles. Suburban (magenta) and city (red) cycles spend relatively little time at high speeds in comparison to highway/interstate (blue) driving cycles, in which a plentiful amount of exhaust waste heat is available.

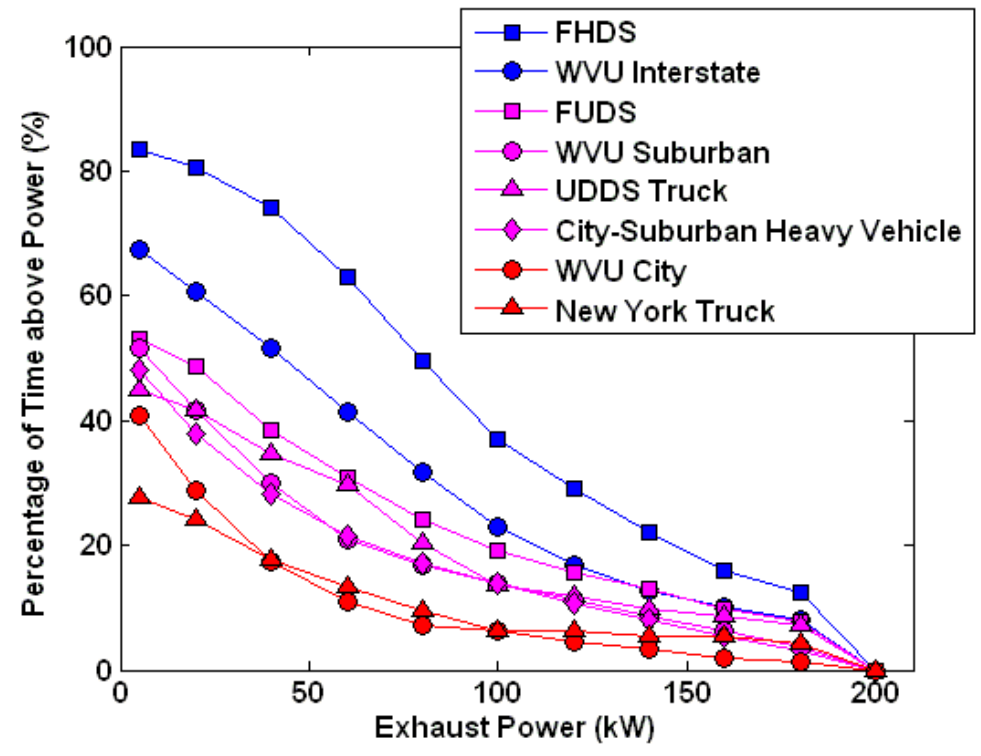

Figure 8. Percentage of time that a Class 8 truck spends above various levels of engine power for various driving cycles. Although city (red) and suburban (magenta) driving cycles have frequent acceleration events, they require much lower engine power settings when compared with higher-speed highway/interstate cycles (blue). 
For a given duty cycle, or percentage of time spent at some level of exhaust power, it is possible to calculate the average amount of electrical power generated by a TE system. Assuming a fixed conversion efficiency, $\eta_{T E ~ s y s}$, and maximum power rating, $P_{\max }$, TE sys, the average electrical power generated by the TE system is

$$
P_{\text {elec }}=f_{v} \cdot \max \left(P_{\max , T E \text { sys }}, \eta_{T E \text { sys }} P_{\text {exh }}\right)+\left(1-f_{v}\right) \cdot \eta_{T E \text { sys }} P_{\text {exh }, 0},
$$

where $f_{v}$ is the percentage of time spent at exhaust waste heat $P_{\text {exh }}$, and $P_{\text {exh, },}$ is the exhaust waste heat produced by idling the engine. For a Class 8 truck with $\eta_{T E} s y s=10 \%$, Figure 9 graphically depicts the equation above with contours of $P_{\text {elec }}(\mathrm{kW})$ versus $f_{v}$. The maximum power rating, $P_{\max }$, TE sys, appears on the left y-axis; consequently, contours of $P_{\text {elec }}$ are unobtainable if they occur above a horizontal line drawn to intersect a chosen value of $P_{\max }$, TE sys. For reference, limits on TE system power output during constant-speed driving are given on the right $y$-axis.

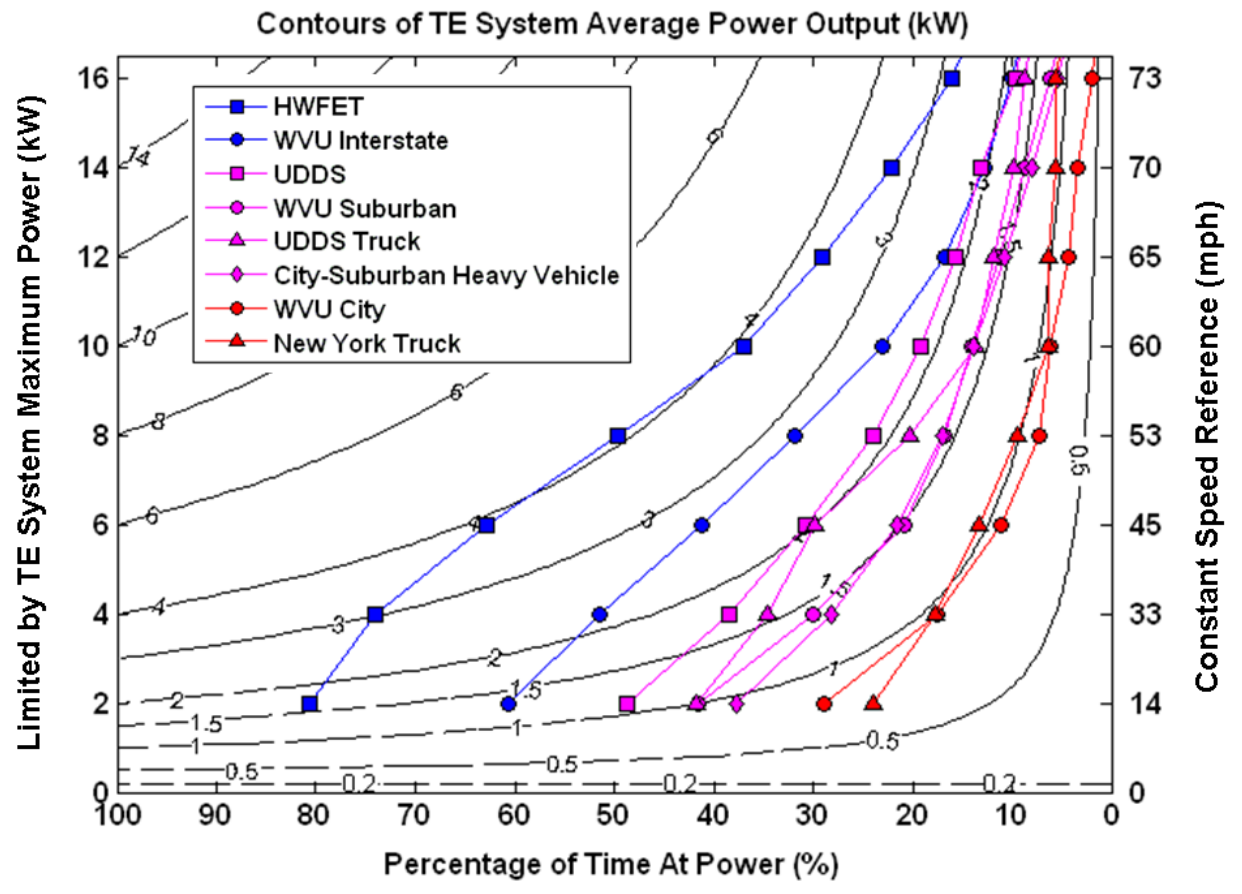

Figure 9. Contour lines showing average electrical power, $P_{\text {elec, avg. }}(\mathrm{kW})$, generated by a TE system with conversion efficiency, $\eta_{T E}$ sys. $=10 \%$ for a Class 8 truck. Duty cycle (x-axis) is the fraction of time spent driving at a constant speed $(100 \%)$ versus idling $(0 \%)$. Left $y$-axis gives limits on $P_{\text {elec, avg. }}$ as a result

of the maximum power rating of the TE system, $P_{\max }$, TE sys. . Right y-axis gives limits on $P_{\text {elec, avg. }}$ for

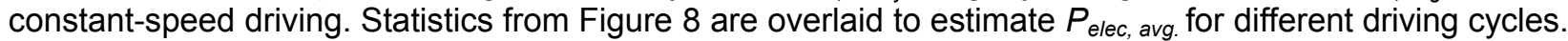

As an example, consider a Class 8 truck traveling at a 40 -mph constant speed and producing roughly $55 \mathrm{~kW}$ of exhaust power. As long as the $10 \%$ efficient TE system is sized sufficiently to capture this amount of power (i.e., $P_{\max }, T E$ sys $\geq 5.5 \mathrm{~kW}$ ), the TE system will produce $P_{\text {elec }}=5.5$ $\mathrm{kW}$. If the Class 8 truck is driven half the time at $40 \mathrm{mph}$ and is idled half the time at zero speed (i.e., $f_{v}=50 \%$ duty cycle), the TE system will produce, on average, approximately $P_{\text {elec }}=2.8 \mathrm{~kW}$. 
Figure 9 is overlaid with exhaust power statistics from Figure 8 to provide an approximation of how much electricity a $10 \%$ efficient TE system could produce for each of the eight driving cycles. For a specific driving cycle, the ideal TE system size lies in the region where that driving cycle's time-at-exhaust power statistic reaches a maximum with respect to the average electrical power contours. Figure 9 shows that, for the most waste-heat-intensive cycle (the highway fuel economy test, or HWFET), the $10 \%$ efficient TE system can produce at most $P_{\text {elec }}=4.1 \mathrm{~kW}$ electricity on average. Generating this level of electricity requires a TE system rated somewhere in the range of $P_{\max }, T E$ sys $\approx 7$ to $9 \mathrm{~kW}$ to capture enough of the high-speed and acceleration exhaust power peaks to make up for time spent at low speeds and/or idling. Sizing the TE system any larger generates incrementally less additional electricity.

Figure 9 shows that relatively small amounts of electrical power are available in city driving situations as a result of limited waste heat and low TE system conversion efficiency. For a 10\% efficient TE system, the least waste-heat-intensive cycle (West Virginia University, or WVU City) would produce $P_{\text {elec }} \approx 0.95 \mathrm{~kW}$ electricity, using a system of size $P_{\max }$, TE sys $\approx 6 \mathrm{~kW}$. Extending these results to TE systems with various conversion efficiencies $\left(\eta_{T E}\right.$ sys $=5 \%, 10 \%$, and $15 \%$ ), Table 3 quantifies the amount of electrical power achievable for city, suburban, and highway driving cycles. Near-term TE systems could be $3 \%$ to $6 \%$ efficient, so it is clear that generating sufficient electricity to replace the Class 8 truck's $0.7 \mathrm{~kW}$ alternator is not possible in the near term.

Table 3. Average TE System Electrical Power for a Class 8 Truck under Different Driving Scenarios and TE System Conversion Efficiencies ${ }^{a}$

\begin{tabular}{lccc}
\hline & $\eta_{\text {TE sys. }}=5 \%$ & $\eta_{\text {TE sys. }}=10 \%$ & $\eta_{\text {TE sys. }}=15 \%$ \\
\hline Interstate driving & $1.4-2.0 \mathrm{~kW}$ & $2.7-4.1 \mathrm{~kW}$ & $4.1-6.1 \mathrm{~kW}$ \\
Suburban driving & $0.7-1.0 \mathrm{~kW}$ & $1.5-2.1 \mathrm{~kW}$ & $2.2-3.1 \mathrm{~kW}$ \\
City driving & $0.4-0.5 \mathrm{~kW}$ & $0.9-1.1 \mathrm{~kW}$ & $1.4-1.6 \mathrm{~kW}$ \\
\hline
\end{tabular}

a. Ranges shown depend on the driving cycle.

For a conventional, non-hybrid-vehicle platform with minimal onboard electrical energy storage and no backup generator other than the alternator, the amount of accessory-electrification possible will be constrained by how much electricity a combined alternator and TE system can rapidly generate under a worst-case situation of cold-start, city driving. A comparison of coldand hot-start urban dynamometer driving schedule (UDDS) chassis dynamometer data sets for a Class 8 truck indicated that it takes about 8 minutes for the engine and exhaust system to warm up to pseudo-steady-state following a cold start (not shown). The effect of the cold start is thus approximated using an 8-minute slew rate from zero exhaust power to full exhaust power as predicted by the steady-state waste heat model.

For TE system conversion efficiencies of $\eta_{T E}$ sys $=5 \%, 10 \%$, and $15 \%$, Table 4 presents the amount of electrical accessories that can be powered reliably by a combined battery/alternator/TE system under the cold-start, city driving scenario mentioned earlier. In each case, the maximum rated power, $P_{\max }$, TE sys, is sized to provide good waste heat recovery on city driving cycles, as discussed for Figure 9. In the most realistic TE system scenario today-e.g., $5 \%$ efficiency - only $0.55 \mathrm{~kW}$ of the Class 8 truck's $7.1 \mathrm{~kW}$ total accessory load can be electrified. Forty-three watt-hours of battery energy are required to partially power the $0.55 \mathrm{~kW}$ of electrical accessories for the first 10 to 12 minutes of city driving following a cold start. 
either (1) used immediately while the vehicle is operated at high speeds or (2) stored in large batteries for future low-speed driving. This challenge can be partially overcome by electrifying accessories having loads that increase with vehicle speed. In the extreme case, the system could help drive the electric traction motors of a hybrid electric powertrain. Another possibility is to couple the TE system with other vehicle systems that require substantial onboard energy storage and charge while the vehicle is being driven. A no-idle sleeper cab system that powers hotel loads from a bank of batteries (rather than idling the truck engine) is an example of this type of possible system.

\subsection{Conclusions}

A combined vehicle model and engine waste heat model were used to compare various accessory electrification scenarios for four different conventional vehicle platforms: a midsize car, a midsize sport utility vehicle, a Class 4 truck, and a Class 8 truck. The Class 8 truck-which has a large amount of waste heat, low mass sensitivity, and a high number of miles traveled per yearwas found to be most attractive for early market penetration of a TE waste heat recovery system.

For the Class 8 truck, a near-term-achievable TE system with 5\% overall efficiency (taking into account heat exchangers, pumps, and other ancillary losses) can be expected to generate from 0.4 $\mathrm{kW}$ for city driving cycles to $2.0 \mathrm{~kW}$ for highway driving cycles. This amount of electrical power is insufficient to eliminate the alternator, particularly during cold-start, city driving. Depending on the TE system conversion efficiency, the fuel savings expected by integrating a modest TE system into a conventional Class 8 truck platform are on the order of $2 \%$ to $3 \%$. A suitable battery with usable energy on the order of 40 to $80 \mathrm{~W}$-h must also be selected to source/sink electricity during worst-case transients. Current TE system costs of $\$ 3,000$ to $\$ 6,000 / \mathrm{kW}$ must be reduced substantially, to about $\$ 450 / \mathrm{kW}$ for the Class 8 truck platform application, to become economically justifiable.

For conventional vehicle platforms, fuel savings are limited by the amount of accessories that can be electrified. In turn, the amount of accessories that can be electrified is limited by all of the following:

- Maximum rated power of the alternator

- Amount of waste heat in the exhaust, particularly in cold-start city driving scenarios

- Conversion efficiency of the TE system

- Size of the battery

- Maximum rated power of the TE system.

Future analyses should focus on specific driving scenarios that produce large amounts of waste heat (e.g., a Class 8 truck used for over-the-road, interstate hauling). Additional analyses should also ensure that the complete system is robust to all other types of driving (e.g., a Class 8 truck driving in the city without a trailer).

Vehicle configurations well-matched for TE technology are not directly addressed in this work. These configurations include vehicles in which accessory loads increase with vehicle speed, a large alternator or battery is already present, and a hybrid electric powertrain is present with 
electric traction motors, onboard energy storage, and a large (not downsized) engine. Each of these scenarios holds potential for additional fuel savings beyond $2 \%$ to $3 \%$. Each case would require a larger TE system with more stringent cost requirements than the $\$ 450 / \mathrm{kW}$ presented here, however. Finally, efforts should be made to reduce or eliminate TE system ancillary devices, such as heat exchangers, that increase system mass and volume.

\subsection{References}

[1] Hendricks, T.J.; Johnson, V.H.; Keyser, M.A. "Heat Generated Cooling Opportunities." Available online at www.nrel.gov/vehiclesandfuels/ancillary_loads/pdfs/heat_cooling.pdf; accessed January 22, 2009.

[2] Lambert, M.A.; Jones, B.L. "Automotive Adsorption Air Conditioner Powered by Exhaust Heat. Part 1: Conceptual and Embodiment Design." Proceedings of the Institution of Mechanical Engineers, Part D: Journal of Automobile Engineering 220 (7); pp. 959-972.

[3] Garrett, S.L. "Resource Letter: TA-1: Thermoacoustic Engines and Refrigerators." American Journal of Physics 2 (1), 2004; pp. 11-17.

[4] Swift, G. "Thermoacoustics: A Unifying Perspective for Some Engines and Refrigerators." Journal of the Acoustical Society of America 113 (2379), 2003.

[5] Winters, J. "Heat to Power, Directly." Mechanical Engineering, August 2008.

[6] Yang, J. "Potential Applications of Thermoelectric Waste Heat Recovery in the Automotive Industry." IEEE $24^{\text {th }}$ International Conference on Thermoelectrics, Clemson, South Carolina, 2005.

[7] Bass, J.; Elsner, N.; Ghamaty, S.; Jovanovic, V.; Krommenhoek, D. "High Efficiency Quantum Well Thermoelectrics for Waste Heat Power Generation.” Diesel Engine-Efficiency and Emissions Research Conference, Chicago, Illinois, 2005.

[8] LaGrandeur, J. "Automotive Waste Heat Conversion to Electric Power using Skutterudites, TAGS, PbTe and Bi2Te3." IEEE 25th International Conference on Thermoelectrics, Vienna, Austria, 2006.

[9] Smith, K.; Thornton, M. "Feasibility of Onboard Thermoelectric Generation for Improved Vehicle Fuel Economy.” Diesel Engine-Efficiency and Emissions Research Conference, Detroit, Michigan, 2007.

[10] Smith, K.; Thornton, M. "Feasibility of Thermoelectrics for Waste Heat Recovery in Hybrid Vehicles." $23^{\text {rd }}$ International Electric Vehicle Symposium, Anaheim, California, 2007.

[11] Sagr, K.M.; Mansour, M.K.; Musa, M.N. "Thermal Design of Automobile Exhaust Based Thermoelectric Generators: Objectives and Challenges." Int. J. Automotive Technology 9 (2), April 2008; pp. 155-160. 
[12] Pollock, D.D. "Thermoelectric Phenomena." In CRC Handbook of Thermoelectrics. D.M. Rowe, Ed. Boca Raton, FL: CRC Press, 1995.

[13] Hi-Z Technology, Inc. "Thermoelectric Modules." Available online at http://www.hiz.com/products.php; accessed January 22, 2009.

[14] Bell, L. "BSST Waste Heat Recovery Program." U.S. Department of Energy 2008 Vehicle Technologies Program Annual Merit Review, February 25-28, 2008.

[15] Fairbanks, J. Personal communication. 2007.

[16] Anderson, J.; Bertram, K.; Santini, D.; Vyas, A. "Diesel Trucks - Then and Now.” Diesel Engine Efficiency and Emissions Research Conference, Chicago, Illinois, 2005. 


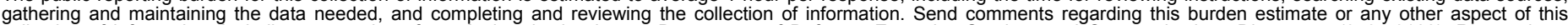

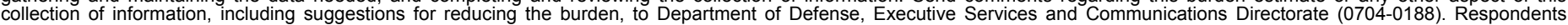

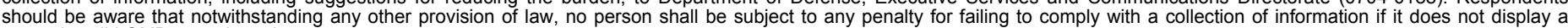

should be aware that notwithstanding

PLEASE DO NOT RETURN YOUR FORM TO THE ABOVE ORGANIZATION.

\begin{tabular}{l|l|l|}
\hline 1. REPORT DATE (DD-MM-YYYY) & 2. REPORT TYPE & 3. DATES COVERED (FrOm - TO)
\end{tabular} April 2009

Technical Report

4. TITLE AND SUBTITLE

Feasibility of Thermoelectrics for Waste Heat Recovery in

Conventional Vehicles 5a. CONTRACT NUMBER

DE-AC36-08-GO28308

5b. GRANT NUMBER

5c. PROGRAM ELEMENT NUMBER

5d. PROJECT NUMBER

NREL/TP-540-44247

5e. TASK NUMBER

FC08.2000

5f. WORK UNIT NUMBER
7. PERFORMING ORGANIZATION NAME(S) AND ADDRESS(ES)

National Renewable Energy Laboratory

1617 Cole Blvd.

Golden, CO 80401-3393
8. PERFORMING ORGANIZATION REPORT NUMBER

NREL/TP-540-44247

9. SPONSORING/MONITORING AGENCY NAME(S) AND ADDRESS(ES)

10. SPONSOR/MONITOR'S ACRONYM(S) NREL

11. SPONSORING/MONITORING AGENCY REPORT NUMBER

12. DISTRIBUTION AVAILABILITY STATEMENT

National Technical Information Service

U.S. Department of Commerce

5285 Port Royal Road

Springfield, VA 22161

13. SUPPLEMENTARY NOTES

14. ABSTRACT (Maximum 200 Words)

Thermoelectric (TE) generators convert heat directly into electricity when a temperature gradient is applied across junctions of two dissimilar metals. The devices could increase the fuel economy of conventional vehicles by recapturing part of the waste heat from engine exhaust and generating electricity to power accessory loads. A simple vehicle and engine waste heat model showed that a Class 8 truck presents the least challenging requirements for TE system efficiency, mass, and cost; these trucks have a fairly high amount of exhaust waste heat, have low mass sensitivity, and travel many miles per year. These factors help maximize fuel savings and economic benefits. A driving/duty cycle analysis shows strong sensitivity of waste heat, and thus TE system electrical output, to vehicle speed and driving cycle. With a typical alternator, a TE system could allow electrification of $8 \%-15 \%$ of a Class 8 truck's accessories for $2 \%-3 \%$ fuel savings. More research should reduce system cost and improve economics.

15. SUBJECT TERMS

thermoelectrics; waste heat recovery; advanced vehicle systems; fuel economy

\begin{tabular}{|c|c|c|c|c|}
\hline \multicolumn{3}{|c|}{ 16. SECURITY CLASSIFICATION OF: } & \multirow{2}{*}{$\begin{array}{l}\text { 17. LIMITATION } \\
\text { OF ABSTRACT } \\
\text { UL }\end{array}$} & \multirow{2}{*}{$\begin{array}{l}\text { 18. NUMBER } \\
\text { OF PAGES }\end{array}$} \\
\hline $\begin{array}{l}\text { a. REPORT } \\
\text { Unclassified }\end{array}$ & $\begin{array}{l}\text { b. ABSTRACT } \\
\text { Unclassified }\end{array}$ & $\begin{array}{l}\text { c. THIS PAGE } \\
\text { Unclassified }\end{array}$ & & \\
\hline
\end{tabular}

19a. NAME OF RESPONSIBLE PERSON
19b. TELEPHONE NUMBER (Include area code)

